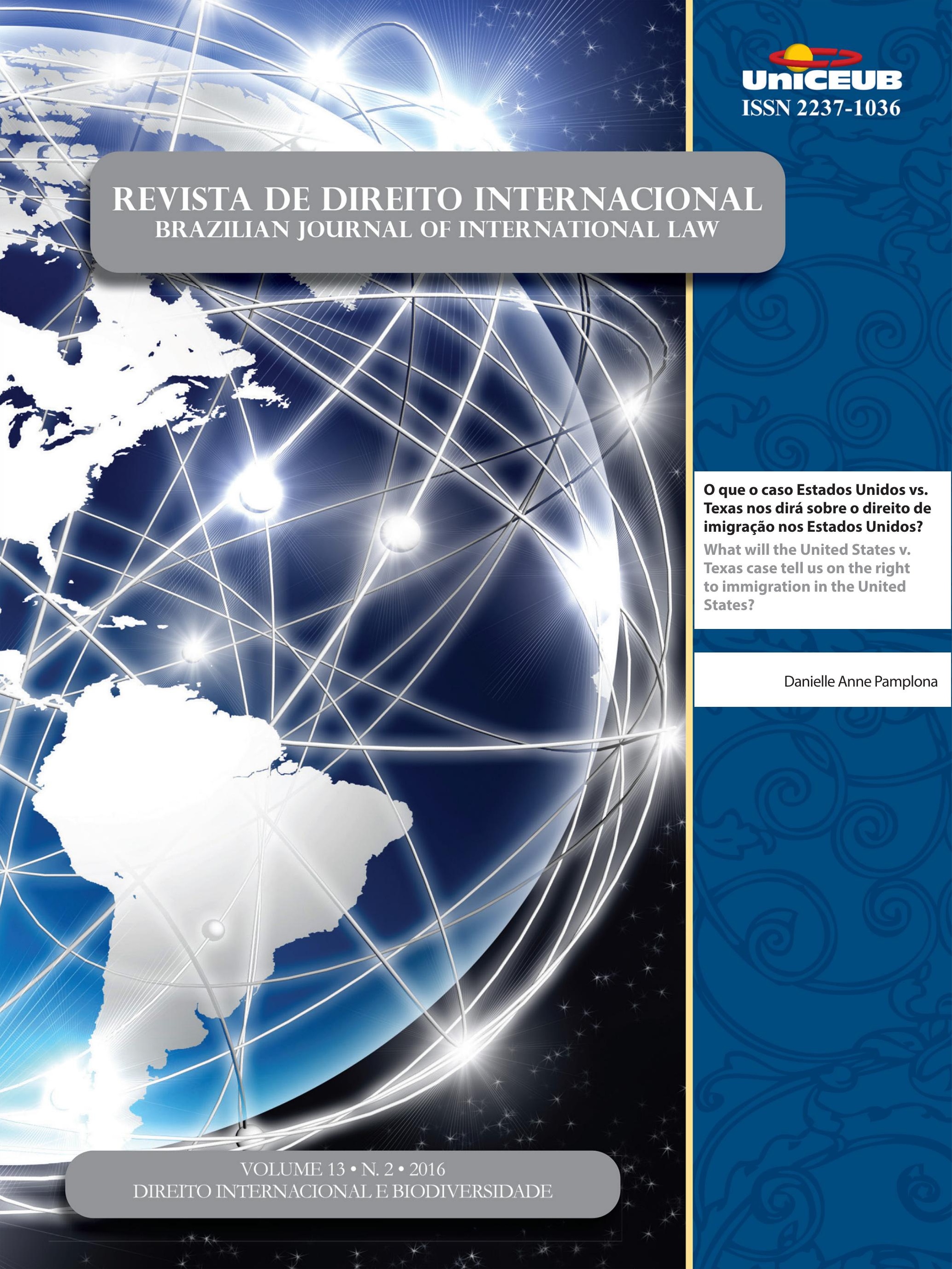




\section{Sumário}

CRÔNICAS DE DIREITO INTERNACIONAL PRIVADO 3 Gustavo Ferreira Ribeiro, Inez Lopes Matos Carneiro de Farias, Nadia de Araujo e Marcelo De Nardi

EDITORIAL 22

Márcia Dieguez Leuzinger e Solange Teles da Silva

IMPROVING THE EFFECTIVENESS OF LEGAL ARRANGEMENTS TO PROTECT BIODIVERSITY: AUSTRALIA AND BRAZIL .25

Paul Martin, Márcia Dieguez Leuzinger e Solange Teles da Silva

O RECONHECIMENTO DA DIGNIDADE DOS ELEMENTOS DA BIODIVERSIDADE COM BASE NO DIÁLOGO ENTRE O DIREITO INTERNACIONAL E O ORDENAMENTO JURÍDICO BRASILEIRO

Augusto César Leite de Resende

O REGIME INTERNACIONAL DO CLIMA E A PROTEÇÃO AOS “REFUgIADOS CLIMÁTICOS”: QUAIS DESAFIOS DA COP 21?

Ana Carolina Barbosa Pereira Matos e Tarin Cristino Frota Mont'Alverne

A anÁlise do MECANismo REdD+ COM Vistas À MitigaÇÃo dos EFEITOS DAS MUdANÇAS CLIMÁTICAS E À PROTEÇÃO DA DIVERSIDADE BIOLÓGICA FLORESTAL

Diogo Andreola Serraglio e Heline Sivini Ferreira

ECOLABELS DE EFICIÊNCIA ENERGÉtiCA E SUA CONSISTÊNCIA COM A DISCIPLINA DOS PPM's E PROVISÕES dOs Acordos GATT E TBT.

Cristiane Derani e Arthur Rodrigues Dalmarco

ANÁLISIS DEL ORDENAMIENTO JURÍDICO INTERNACIONAL SOBRE PROTECCIÓN DE LOS RECURSOS GENÉTICOS: DESAFIOS Y PERSPECTIVAS EN URUGUAY A PARTIR DE LA IMPLEMENTACIÓN DEL PROTOCOLO DE NAgOYA 115

Alina Celi 
LE RÉGIME INTERNATIONAL DE L'ACCÈS AUX RESSOURCES GÉNÉTIQUES AU PRISME DE L'ENTRÉE

en VIgUeUr du Protocole de NAgoya .............................................................. 131

Rodolpho Zahluth Bastos, Otávio Canto, Karine Galy e Isabelle Vestris

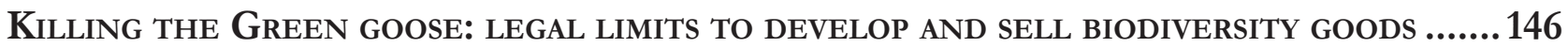
José Augusto Fontoura Costa e Liziane Paixão Silva Oliveira

VÍNCULO SUBSTANCIAL E AS BANDEIRAS DE CONVENIÊNCIA: CONSEQUÊNCIAS AMBIENTAIS DECORRENTES DOS NAVIOS COM REGISTROS ABERTOS ....................................................... 160

Marcos Edmar Ramos Alvares da Silva e André de Paiva Toledo

ANÁLISE DE CONTRATOS PÚblicos SOCIOAMBIENTAIS NO CENÁRIO PORTUGUÊS DE CRISE ECONÔ-

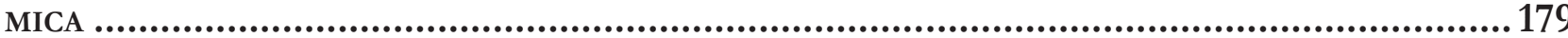

Alice Rocha da Silva e Matheus Passos Silva

A ORganizaÇão do TRATAdo DE COOPERAÇão AMAZÔNICA: UMA ANÁLISE CRÍTICA dAS RAZÕES POR TRÁS DA SUA CRIAÇÃO E EVOLUÇÃO

Paulo Henrique Faria Nunes

O uso de EXPERTS EM Controvérsias ambientais Perante a CorTe InTERnacional de JusTIÇA ........................................................................................................245

Lucas Carlos Lima

Os VIESES dA BIODIVERSIDAdE APRESENTAdos PELO CASO do PARQUE EÓlico DE BALd HiLls ......261 Natália Zampieri e Mariana Cabral

Mining CBD 275

Claire Lajaunie e Pierre Mazzega

Biotecnologia moderna, direito e o pensamento Abissal

Reichardt, F.V., Garavello, M. E. P. E., Molina, S.M.G. e Ballester, M. V. R.

Community Core Values como parâmetro de efetivação dos Princípios da Precaução e da Participação Popular em instrumentos de controle de projeto atividade de alta COMPLEXIDADE AMBIENTAL................................................................................... 314

Michelle Lucas Cardoso Balbino 
Discussões BIOTECNOLÓgICAS QUANTO AOS ORGANISMOS GENETICAMENTE MODIFICADOS NO ÂMBito da OMC: do contencioso ao acordo de vontades entre Argentina e União EuroPEIA

Gustavo Paschoal Oliveira

O Trans-Pacific Partnership Agreement e seus potenciais impactos para a regulação

DA BIODIVERSIDADE NO ÂMBITO TRANSNACIONAL..........................................................375

Mariana Yante Barrêto Pereira

AS ÁREAS PROTEGIDAS TRANSFRONTEIRIÇAS: REFLEXÕES CRÍTICAS ACERCA DE UM USO GEOPOLÍTICO DO DIREITO DA BIODIVERSIDADE.

Rabah Belaidi

O Que o caso Estados Unidos vs. Texas nos dirá sobre o direito de IMigração nos EsTADOS UNIDOS? 409

Danielle Anne Pamplona

Clóvis Beviláqua e a justiça internacional: entre o sim E o Não a Rui Barbosa.... .422 Paulo Emílio Vauthier Borges de Macedo

Possibilidade de delegação de atribuição para a Celebração de Tratados pela RepúbliCa Federativa do Brasil: análise do artigo 84, VIII c/c Parágrafo único da ConstituiÇão FEDERAL

Luciano Monti Favaro e Héctor Valverde Santana

Dignity, ubuntu, HUMANiTY AND AUTONOMOUS WEAPON SYSTEMS (AWS) DEBATE: AN AfRiCAN PERSPECTIVE 460

Thompson Chengeta

DiREITO INTERNACIONAL PRIVADO E O DIREITO TRANSNACIONAL: ENTRE A UNIFICAÇÃO E A ANARQUIA .503

André De Carvalho Ramos

A ilusória ausênCia do termo DépeÇage na JURisprudênCia brasileira de contratos INTERNACIONAIS

Gustavo Ferreira Ribeiro 
O EFEITO DIRETO DAS DIRETIVAS E OS DIREITOS FUNDAMENTAIS........................................535 Lucas Fonseca e Melo e José Levi Mello do Amaral Júnior

DA APLICABILIDADE DO BULK FACTORING AOS GRUPOS DE SOCIEDADES 565 Daniel Amin Ferraz e Leonardo Arêba Pinto

A Questão hermenêutica no direito das GENTES ................................................580 Inocêncio Mártires Coelho 


\title{
O que o caso Estados Unidos vs. Texas nos dirá sobre o direito de imigração nos Estados Unidos?*
}

\author{
What will the United States v. Texas case tell \\ us on the right to immigration in the United \\ States?
}

Danielle Anne Pamplona**

“....we're going to keep focusing enforcement resources on actual threats to our security. Felons, not families. Criminals, not children. Gang members, not a mom who's working hard to provide for her kids. We'll prioritize, just like law enforcement does every day." (Presidente Obama, em Comunicado à nação, sobre imigração, em 20 de novembro de 2014) ${ }^{1}$

\section{Resumo}

O texto discute as questões de fato e de direito envolvidas no caso Estados Unidos vs. Texas, que versa sobre medidas do Poder Executivo em relação à imigrantes ilegais em solo norte-americano. Para isso, esclarece os argumentos de política utilizados por ambas as partes antes de se concentrar nos argumentos jurídicos. O texto se fundamenta nas reflexões mais recentes sobre o direito de imigração, sobre o poder regulamentar do Executivo e o modo de seu exercício. Ao final, são ponderadas as preocupações humanitárias refletidas nos Planos do Poder Executivo e as consequências da decisão do Poder Judiciário sobre os direitos humanos, concluindo que a decisão da Suprema Corte poderá abraçar a proteção dos direitos humanos, mantendo, em solo americano, cidadãos que não conhecem outro local para chamar de casa, sem qualquer desvio dos comandos legais e constitucionais.

Palavras-chave: Direito de Imigração. Suprema Corte dos Estados Unidos. Regulamentação. Poder Executivo.

* Recebido em 07/03/2016

Aprovado em 07/06/2016

** International Visiting Scholar na Washington Law School da American University em Washington, D.C., Bolsista da Capes-Brasil; Professora Titular do Programa de Pós-Graduação em Direito da Pontifícia Universidade Católica do Paraná, Doutora em Direito pela Universidade Federal de Santa Catarina. E-mail: dapamplona@pamplonaebraz.com.br

\section{Abstract}

The paper discusses fact and legal issues arising in the case United States vs. Texas, that deals with measures of the Executive Branch regarding illegal immigrants on US soil. Therefore, it clarifies the political arguments used by both parties before focusing on legal arguments. The text is grounded on the latest thinking on immigration rights, on the Executive regulatory power

1 Tradução livre da autora: “[...] continuaremos focando os recursos em ameaças reais à nossa segurança. Criminosos, não família. Contraventores, não crianças. Membros de gangues, não uma mãe que está trabalhando duro para prover suas crianças. Nós priorizaremos, exatamente como os oficiais que aplicam a lei fazem todos os dias." OBAMA, Barack. Pronunciamento à nação em 20.11.2014. Disponível em: <https://www.whitehouse.gov/ thepress-office/2014/11/20/remarks-president-address-nation-immigration>. Acesso em: 10 jan. 2016. 
and on its exercise. In the end, humanitarian concerns reflected in the plans of the Executive branch and the consequences of the Judiciary ruling on human rights are considered, to conclude that the Supreme Court may embrace the human rights protection, keeping on American soil citizens who do not know another place to call home, without any deviation from the legal and constitutional provisions.

Keywords: Immigration law; US Supreme Court; regulation; Executive Branch.

\section{INTRODUÇão}

A Suprema Corte norte-americana tem à sua frente um grande caso, sob o ponto de vista do direito internacional dos direitos humanos, para resolver. Ela enfrentará o que se espera seja um dos casos mais impactantes no direito de imigração estado-unidense. A solução que dará afetará a vida de milhares de imigrantes que hoje vivem nos Estados Unidos sem autorização para tanto, mas que têm vínculos extremamente fortes com o país. A decisão da Suprema Corte definirá o futuro de crianças que só conhecem os Estados Unidos como terra natal, de seus pais, de pessoas que tem trabalhado e contribuído para o crescimento de suas comunidades, entre tantas outras que poderão demonstrar sua conexão com o país.

No início do ano de 2016, a Suprema Corte concedeu certiorari ao governo federal, ou seja, decidiu que irá julgar o caso Texas vs. Estados Unidos, o que ocorrerá, ainda, no primeiro semestre ${ }^{2}$. A disputa teve sua gênese em novembro de 2014 quando o Presidente Obama anunciou uma série de orientações relativas à política de imigração, conhecidas como, em tradução livre, "Plano de Responsabilização de Imigração" ou, em inglês, Immigration Accountability Executive Action ${ }^{3}$. $\mathrm{O}$

2 A Suprema Corte, composta por nove julgadores, está, no momento de elaboração do presente texto, composta por somente oito, por força do recente falecimento do Juiz Antonin Scalia. Assim, se o caso contar com quatro votos a favor e quatro votos contra, permanecerá válida a decisão da Corte de Apelações do 5o Circuito, sem efeito de precedente.

3 São necessárias duas palavras sobre a tradução. Em primeiro lugar, o termo 'executive action' está traduzido para Plano, eis que não se trata de um documento vinculante, não é um tipo legislativo editado pelo Presidente. Em segundo lugar, o termo 'accountability' diz respeito à justificativa de que é preciso agir para que alguns milhares de imigrantes que estão no país sem documentos, há alguns anos, cerne dessa grande política é a expansão de um plano já existente 4 e em execução, denominado "Ação Postergada para Ingressantes Infantes", ou DACA - Deferred Action for Childhood Arrivals e do plano denominado "Ação Postergada para pais de americanos" ou DAPA, sigla em inglês para Deferred Action for Parents of Americans, iniciativa para pais de cidadãos americanos e residentes permanentes legais que atendessem a determinados critérios. O termo deferred action é tido como "[...] em geral, um ato de discricionariedade que suspende os procedimentos de deportação contra um indivíduo ou um grupo de indivíduos para um período de tempo específico; ele não pode resolver a questão do status imigratório do indivíduo" 5 .

Assim que anunciado, o plano foi objeto de ação promovida no Texas por vários Estados, com pedido liminar sob o principal argumento de que um de seus efeitos seria a obrigatoriedade de emissão de milhares de carteiras de motorista o que imporia um ônus irreversível aos Estados, se, ao final, fosse decidido no mérito que os planos não poderiam ser implementado. Em fevereiro de 2015, o pedido foi deferido para suspender a execução do DAPA e do DACA expandido, o que foi confirmado por maioria e pela Corte de Apelações do $5^{\circ}$ Circuito. Isso significa dizer que os planos não podem ser executados em qualquer Estado do país.

O direito aplicável ao caso é a Lei de Imigração e Nacionalidade (Immigration and Nationality Act - INA) ${ }^{6}$, datada de 1952 e que tem sido, ao longo do tempo, objeto de várias discussões no Congresso Nacional para que sejam aprovadas alterações substanciais, sem muito sucesso nos dias atuais. Desde 2001, várias foram as tentativas de aprovação no Congresso Nacional do DREAM Act (acrônimo para o nome, em inglês, Development, Relief, Education for Alien Minors - Desenvolvimento, ajuda e educação para menores estrangeiros), que permitiria aos menores que cumprissem com

possam ser chamados a contribuir, pagando os impostos devidos.

4 O DACA foi anunciado pelo Presidente Obama em 2012.

5 Tradução livre do original: “...generally an act of prosecutorial discretion to suspend removal proceedings against a particular individual or group of individuals for a specific timeframe; it cannot resolve an individual's underlying immigration status." WADHIA, Shoba Sivaprasad. The Role of Prosecutorial Discretion in Immigration Law. 31 Immigration \& Nationality Law Review, p. 961-1017, 2010. p. 981.

6 U.S. DEPARTMENT OF HOMELAND SECURITY. Immigration and Nationality Act. Disponível em: <https://www.uscis.gov/ ilink/docView/SLB/HTML/SLB/act.html>. Acesso em: 05 jun. 2016. 
vários requisitos, entre eles o de estarem matriculados e frequentando instituição de ensino, a permanência legal no país. Como até 2012 o Congresso não chegara a um acordo ${ }^{7}$, o Presidente Obama anunciou o plano para suspender a deportação de menores estudantes que atendessem a determinados critérios, alguns coincidentes com aqueles do DREAM Act. Esse plano é o DACA, acima mencionado. Agora, o Presidente edita o DAPA e uma expansão no DACA de 2012 e isso não deixa de ser uma resposta a anos de inércia do Congresso. Essa atuação, no entanto, não foi bem recebida pelos Estados que, agora, discutem, em juízo, se o Presidente tem ou não a competência para exercer sua autoridade discricionária para execução de regras de imigração e se, tendo a competência, a exercitou dentro dos parâmetros legais.

A atitude da administração de Obama indica a vontade em priorizar e distinguir entre os diferentes tipos de casos de imigração com que os oficiais lidam todos os dias. E são muitos os oficiais que se deparam com imigrantes sem documentos e que, consequentemente, precisam decidir se irão ou não dar início ao processo de deportação. A legislação americana permite que a decisão seja tomada por esses oficiais, impondo critérios mínimos para tanto. Assim, desde o oficial de fronteira até o policial que para um carro em uma estrada tomam decisões sobre imigração. Os planos de Obama estabelecem critérios para que os oficiais não iniciem o processo, sob o argumento de que devem concentrar seus esforços para deportar imigrantes que representem uma ameaça. Mas e o que faz desse caso algo tão importante para os imigrantes e porque ele tem chamado tanta atenção?

Para compreender, é preciso saber que os Estados Unidos contam, hoje, com mais de onze milhões de imigrantes sem autorização em seu território. Na teoria, todos deveriam ser expulsos do país. Não há, no entanto, recursos suficientes para implementar tal ação. Em verdade, na prática, o orçamento da União para o Departamento de Segurança Nacional Departament of Homeland Security (DHS), responsável pela execução de políticas de imigração, permite que se expulse so-

7 É preciso chamar a atenção para o fato de que não se trata, tão somente, dos membros do Congresso chegarem a um acordo entre si. Em verdade, trata-se, também, do fato de que o Presidente Obama tem dificuldades em aprovar medidas no Congresso desde 2011, quando perdeu a maioria democrata em ambas as Casas. mente quatrocentos mil imigrantes por ano ${ }^{8}$. Fica evidente, portanto, que o Executivo deve, todos os anos, fazer uma opção acerca de quem serão os imigrantes-alvo da política de expulsão. E é isso o que, ano após ano, as administrações fazem. E a opção adotada por esse governo foi de priorizar criminosos e dar um fôlego à imigrantes estudantes e trabalhadores, que podem, ao final, contribuir para o desenvolvimento e crescimento da nação.

Com base nesse caso, o presente texto pretende demonstrar que a legislação atual não consegue abranger as diferentes razões pelas quais os imigrantes devem ou não receber tratamento que lhes permitam ficar no país, sem o receio de deportação, por um determinado prazo. De fato, a legislação é demasiada ampla e sempre convidou o Executivo à regulamentação. Assim, o texto, na seção 2 , indica quais os fundamentos de política que estão por trás da disputa, buscando contextualizá-los diante da necessária proteção de direitos humanos. $\mathrm{Na}$ terceira seção, são enfrentados os argumentos jurídicos que estão nas mãos da Suprema Corte e como eles tem sido rebatidos pelas partes. Por fim, o texto procura demonstrar que a atual administração não atuou de modo diferente das anteriores, agindo de acordo com o poder e o dever que tem de fazer cumprir as leis. Ora, se a legislação demanda a expulsão de quem está no território sem autorização, permite que os recursos finitos sejam direcionados a determinadas pessoas. Por outro lado, a administração não deixou de cumpriu com os requisitos legais impostos a esse tipo de atuação, como restará demonstrado. Espera-se que a Suprema Corte possa reconhecer a legalidade e a constitucionalidade dos atos do Presidente, fazendo prevalecer a proteção dos direitos humanos dos imigrantes que há tanto tempo estão em solo americano.

\section{ENTENDENDO O QUE ESTÁ EM JOGO}

Há que se distinguir, dentre os fundamentos utilizados pelas partes, os argumentos políticos daqueles

8 As orientações do DACA são aplicáveis a uma pequena fração desses milhões de imigrantes ilegais, segundo HOEFER, Michael; RYTINA, Nancy; BAKER, Bryan. Estimativa da população de imigrantes sem autorização vivendo nos Estados Unidos. Escritório de Estatísticas do Departamento de Segurança Nacional. Disponível em: <http:// www.dhs.gov/xlibrary/assets/statistics/publications/ois_ill1pe 2011.pdf>. Acesso em: 20 fev. 2016. 
que se fundamentam em dispositivos legais. Por vezes, a fundamentação utilizada por ambas as partes escora-se em situações fáticas, em realidades observadas e medidas no tempo. Na seara política, os Estados alegam que os planos anunciados pelo Presidente levarão a uma grande onda de imigração; que os cartéis de droga promoverão um aumento do tráfico humano, o que na prática, representaria, portanto, um aumento do ônus dos Estados de combater crimes; e, por fim, alegam que os Estados terão maiores gastos com agentes policiais, saúde, educação, licenças para trabalho, carteiras de motorista, entre outros.

Em primeiro lugar, há que se mencionar que a alegação de que haveria um aumento na imigração é negada pelas evidências empíricas. De fato, mesmo com o DACA, editado em 2012, os fatos demonstram que a violência e o medo de perseguição têm levado as famílias a voltarem para a América Central' .

Em segundo lugar, não há evidências de que a permissão para que essas pessoas fiquem no país, sem medo de deportação, influencie os níveis de ocorrência de tráfico de pessoas. O tráfico ocorre quando a pessoa, em situação vulnerável, é iludida pela promessa de uma vida melhor e se deixa levar a um outro país. Ao chegar a esse novo país, o indivíduo encontra condições muito diferentes das que lhe foram prometidas. Assim, o tráfico, de acordo com a Convenção das Nações Unidas contra o Crime Organizado Transnacional, conhecida como Convenção de Palermo, e seu Protocolo Adicional relativo ao tráfico de pessoas, estabelece que o tráfico é um crime que ocorre quando há recrutamento de pessoas com o objetivo de sua exploração sob ameaça ou fraude. Em geral, ele está associado com uma condição de vulnerabilidade, econômica ou social, que não dá à pessoa outra alternativa senão buscar uma vida melhor em outro local. O programa do Presidente Obama regulariza a situação daqueles que já vivem no país, não alterando a situação de indivíduos em outros países que pudessem se sentir mais atraídos do que antes pela vida nos Estados Unidos.

Em terceiro lugar, a alegação de que haveria um necessário aumento nos gastos dos Estados com serviços

9 Há algumas pesquisas demonstrando a queda na imigração ilegal, como a feita pelo Pew Research Center. What do we know about illegal immigration from Mexico? Disponível em: < http://www.pewresearch.org/fact-tank/2015/11/20/what-we-know-about-illegalimmigration-from-mexico>. Acesso em: 25 jan. 2016. só poderia ser realmente mensurada se fosse apresentado o que representam estas pessoas para a economia em termos de tributos recolhidos. Além disso, a Magistrada da Suprema Corte, Juíza Sonia Sotomayor, ao ouvir o Procurador-Geral do Estado do Texas referir-se, com frequência, aos 'profundos impactos econômicos' da medida, observa que "[A]queles quase onze milhões de estrangeiros sem autorização estão aqui nas sombras. Eles estão afetando a economia queiramos ou não." ${ }^{10}$

No que tange aos motivos políticos para a ação do Presidente, estão os argumentos da necessidade de regulamentar a vida de milhares de imigrantes que há muito estão no país, trabalhando ou cuidando de dependentes e a necessidade e a vontade de lhes aliviar do medo de serem deportados. Estima-se que a ação do Presidente Obama atingiria cerca de cinco milhões de imigrantes, excluindo-os somente temporariamente - por três anos - desta possibilidade de deportação.

Além disso, o Governo argumenta que esses planos foram desenhados para que famílias fossem mantidas unidas, mas se espera, como efeito colateral, que eles aumentem o Produto Interno Bruto do país, o recolhimento de imposto sobre a renda e os salários. Essa é uma consequência da regularização da situação destas pessoas que já estão no país.

Por fim, o Executivo ainda traz o argumento da falta de recursos para cumprir a lei. De fato, não há recursos financeiros e humanos ${ }^{11}$ para efetuar a deportação de todos os imigrantes sem documentação que estão no país e, justamente por isso, a lei permite que a administração exerça, com discricionariedade, o poder de estabelecer grupos prioritários para ações de deportação ${ }^{12}$.

10 The Supreme Court of United States. Arguments Transcripts. Argument Session: April 18, 2016, p. 46. Disponível em: <http://www. supremecourt.gov/oral_arguments/argument_transcripts/15-674_ h3dj.pdf>. Acesso em: 05 jun. 2016.

11 A Suprema Corte já levou em consideração a questão dos recursos disponíveis para implementar uma lei no caso Heckler $v$. Cheney, afirmando que a avaliação da 'discricionariedade' envolvida na execução de leis por membros do executivo envolve um balanceamento complexo dos interesses do poder executivo e dos recursos disponíveis e que o próprio executivo está, em geral, melhor aparelhado do que as cortes para fazer essa avaliação. Disponível em: <https://supreme.justia.com/cases/federal/us/470/821/case. html>. Acesso em: 15 fev. 2016.

12 E isso não é novidade, trata-se de política de Estado. Já em junho de 2011, a Secretaria do Departamento de Segurança Nacional, Janet Napolitano, anunciou iniciativas para assegurar que a prioridade deste Departamento seria remover do país os indivíduos que representassem perigo para o país. É o que indica o Report 09.09.11 do American Immigration Council. Disponível em: <http://www. 
Um dos grandes argumentos dos opositores da implementação dos planos está na condição adquirida por aqueles que cumprem os critérios para serem abrangidos pelos planos. A alegação é de que a postergação do ato de deportação significaria lhes conceder algum status de imigrante. Mas, por definição, não é o que ocorre. Há uma confusão entre os termos 'presença legal', que impede, momentaneamente, a deportação, e 'status legal', que significa estar no país sob a proteção de um visto específico, de imigrante ou não. Ao requerer que a Suprema Corte aceitasse o caso, o governo explica que, sob suas orientações, inscritas nos planos, a algumas pessoas seria conferida a 'presença legal'. Não há concessão de qualquer status de imigrante aos indivíduos beneficiados com os planos do governo ${ }^{13}$, mas a confusão entre os termos tem sido fundamento para muitos que disputam o direito dos imigrantes.

A possibilidade de ser inclú́do no plano não significa a concessão de cidadania, tampouco sequer é um passo para ela. Em verdade, os planos reconhecem aos imigrantes, tão somente, a possibilidade de ficar no solo americano enquanto a deportação não é promovida pelo prazo especificado. Em outros termos, os planos lhes concedem a condição de presença legal no país.

A disputa é enorme entre os que enxergam as ações do Presidente como um avanço na área de direitos humanos em geral e direito de imigração, em particular, e aqueles que entendem que deve prevalecer o primeiro e mais geral comando da lei que é o de deportação de todo o estrangeiro que esteja em território sem autorização. No geral, isso reflete a ideia de que as regras impostas aos imigrantes devam ser cada vez mais excludentes, conforme alerta Maiquel Ângelo Dezordi Wermuth - ainda que referindo-se às legislações europeias. Para o autor, isso decorre do fato de que "..... imigração é vista como uma "ameaça" diante do enxugamento do Estado de Bem-Estar Social e do consequente "parasitismo" representado pelos imigrantes, bem como diante do medo, cada vez maior, da megacriminalidade, em especial do terrorismo, sempre associado à imigração." ${ }^{14}$

immigrationpolicy.org/just-facts/understanding-prosecutorial-discretion-immigration-law >. Acesso em: 05 jun. 2016.

13 CROW, Melissa. Symposium: Back to immigration basics - Why the DAPA/DACA case is simpler than it seems, SCOTUSblog (Feb. 10, 2016, 12:55 PM). Disponível em: <http://www.scotusblog. com/2016/02/symposium-back-to-immigration-basics-why-thedapadaca-case-is-simpler-than-it-seems>. Acesso em: 20 fev. 2016. 14 WERMUTH, Maiquel Ângelo Dezordi. Direito penal (do autor) e imigração irregular na União Européia: do "descaso" ao
Sem dúvida há uma grande carga de preconceito a guiar os argumentos dos que se opõe a uma política que reconhece estes imigrantes como sujeitos de direitos, para inclúi-los como cidadãos, detentores de direitos, mas também de deveres.

\section{O que está nas mãos da Suprema Corte}

Envolvida por todas essas relevantes alegações, a Suprema Corte terá de definir com quem está o direito neste caso.

A Suprema Corte, ao deferir o certiorari, delimitou os temas sobre os quais deverá se manifestar. Assim, entendeu que deverá definir se um Estado que conceda direitos a todos os estrangeiros que estejam sujeitos à postergação de sua deportação (como é o caso das carteiras de motorista), tem ou não legitimidade, sob o Artigo III da Constituição, para propor a ação e se os Estados cumprem com as condições da ação estabelecidas na Lei de Procedimentos Administrativos, ou seja, se o caso apresenta justiciabilidade. Além disso, a Suprema Corte terá que definir se as orientações estão sujeitas à específica exigência da Lei de Procedimentos Administrativos de atender aos procedimentos de "noticia e comentário" 15 e, por fim, se as orientações violam a "Cláusula do Cuidado" prevista na Constituição ${ }^{16}$. As primeiras questões, sobre legitimidade e justiciabilidade, estão conectadas com a verificação dos requisitos dispostos na lei e jurisprudência para propositura da ação. Em relação ao mérito, e em resumo, trata-se de saber se, em primeiro lugar, o Presidente feriu a cláusula constitucional, chamada de "Cláusula do cuidado" ao exercer seu poder discricionário de regulamentar a lei de Imigrações e, em segundo lugar, se, no caso de ser aplicável, obedeceu os parâmetros da Lei de Procedimentos Administrativos. Nos tópicos seguintes, é feita a análise das questões de mérito indicadas. "excesso" punitivo em um ambiente de mixofobia. Revista de Direito Internacional, v. 8, n. 2, p. 167-204, 2011. Disponível em: <http:// www.publicacoesacademicas.uniceub.br/index.php/rdi/article/ view/1548>. Acesso em: 05 jun. 2016.

15 O significado dessa exigência será explorado na sequência.

16 Supreme Court of the United States. Blog, United States v. Texas. Disponível em: <http://www.scotusblog.com/case-files/cases/ united-states-v-texas/. Acesso em: 25 fev. 2016. 
3.1. A discricionariedade do Poder Executivo e a "Cláusula do cuidado"

Caberá à Corte definir quais os limites do poder do executivo ao implementar politicas públicas. Em verdade, não há qualquer disputa sobre a existência de uma lei de imigração que traz alguns espaços de discricionariedade para sua execução, mas sim, a extensão dessa discricionariedade.

Há, nos Estados Unidos, uma compilação de leis sobre imigração, denominada Lei de Imigração e Nacionalidade (Immigration and Nationality Act - INA) ${ }^{17}$. Essa compilação data de 1952 e é tida como bastante complexa. São, em verdade, quatro títulos distribuídos em quinze capítulos com mais de duzentos artigos. É a junção de todas as leis até então vigentes nos Estados Unidos regendo várias e diversas situações, desde quem pode visitar o país, quem pode migrar, sob quais condições, passando por critérios para naturalização, regras para estudantes estrangeiros, para trabalhadores temporários, até chegar a regras para admissão de asilados e refugiados. Há, ainda, a previsão de quotas anuais de entrada para imigrantes legais, que foram ajustadas com o passar dos anos; ou casos de mitigação da obrigação de deportação com fundamento na união familiar, contribuição para comunidade ou outras causas humanitárias. Por se tratar de compilação feita há tantos anos, é natural que tenha sido emendada, várias vezes, em especial para expandir o acesso aos imigrantes, com base em seu país de origem, ocupação e fatores humanitários, ou em restringi-lo, com base em condenações criminais ou afiliação política, para citar alguns exemplos. Historicamente, há sempre quem critique as emendas, condenando-as por serem muito restritivas ou muito ampliativas, refletindo, em verdade, opiniões sobre raça, economia, cultura e identidade.

As regras sobre imigração são sensíveis aos fatores político e econômico. Em geral, uma economia próspera consegue gerar o suficiente para o financiamento de programas sociais e, nesse período, a abertura para imigrantes não é percebida como uma ameaça. Ao contrário, pode ser mesmo que sejam bem recebidos para ocupar posições no mercado recusadas por nacionais, impulsionados às melhores posições pelo momento

17 National Archives and Records Administration. Constituição dos Estados Unidos. Disponível em: <http://www.archives.gov/exhibits/ charters/constitution_transcript.html>. Acesso em: 15 jan 2016. econômico. Por outro lado, uma visão pessimista da economia em um determinado momento, ou a real percepção, por meio de indicadores econômicos, de que a economia não vai bem, em geral faz com que as leis que abrem espaço para imigrantes sejam percebidas como responsáveis por atrasos na implementação de direitos sociais de nacionais. A política, também, tem um papel a desempenhar. Há as demandas internas e internacionais e os resultados que os políticos esperam ter nas urnas, que poderão levar à diferentes tratamentos de um mesmo tema. Nesse sentido, com o final da Guerra do Vietnam e a crise humanitária que seguia no país, milhares de vietnamitas fugiram e, nos Estados Unidos, a resposta foi a edição pelo Congresso Nacional, em 1980, da Lei dos Refugiados, tratando de reassentamentos, em conformidade com a Convenção relativa ao status de Refugiados de 1951. Em 1986, o Presidente Ronald Reagan assinou a Lei de Reforma e Controle de Imigração, em resposta ao aumento da imigração ilegal e dos esparsos recursos para controlá-la, legalizando a condição de cerca de três milhões de imigrantes em troca da regularização de suas situações trabalhistas. Nos anos seguintes, os Estados Unidos experimentaram um endurecimento das regras em relação aos imigrantes, como a ampliação dos casos para deportação, o aumento do número de critérios e o endurecimento dos critérios existentes para a concessão de qualquer exceção à deportação; e a transformação de várias violações da lei de imigração em crimes. Mas com o surgimento de episódios de guerras civis e violência eclodindo na América Latina e na antiga União Soviética, o tratamento dado aos novos imigrantes e a indignação gerada obrigou o Congresso a alterar, novamente, a legislação, para facilitar sua entrada e estadia. Em 2001, havia planos para uma nova reforma na lei de imigração e para um novo programa que permitisse a estadia temporária de trabalhadores, mas nada disso pôde ser implementado diante do ataque às torres gêmeas em Nova Iorque. Em verdade, a história é bem conhecida a partir daí, com o fortalecimento de leis de segurança nacional e antiterrorismo ${ }^{18}$, que acabaram por restringir a imigração com a intenção de evitar ameaças ao país. A partir daí, o Executivo tem, sem sucesso, tentado aprovar leis que possibilitem que indivíduos que preenchem alguns

18 Sem a menor dúvida, é correto afirmar que o Patriot Act (acrônimo para Lei para unir e fortalecer a América por meio de instrumentos adequados à interceptação e obstrução do terrorismo, em inglês Uniting and Strengthening America by Providing Appropriate Tools Required to Intercept and Obstruct Terrorism Act) é o mais conhecido. 
requisitos não precisem temer a deportação, ainda que temporariamente. No presente caso, os planos anunciados decorrem da inércia do Congresso Nacional. Esse escorço histórico serve para demonstrar que, por diversas vezes, foi a atuação do Executivo que delimitou a lei de imigração.

Mesmo diante de um Congresso atuante, sempre foi reconhecido ao Presidente da República o direito de agir em relação ao tema, orientando como os esforços devem ser conduzidos. $E$ as ações que aliviam a situação de imigrantes, em várias vezes, permitiram, inclusive, que tivessem acesso legal ao mercado de trabalho, como ocorreu com cubanos, sob a administração de Kennedy; ou com vítimas de violência doméstica, por determinação da Lei que tratou de violência contra as mulheres na Administração de Bill Clinton; ou para pessoas sujeitas ao tráfico humano e estudantes afetados pelo Furacão Katrina, sob a administração de George W. Bush ${ }^{19}$.

A iniciativa de expansão do DACA e o DAPA são mais um exemplo do exercício pelo poder executivo de sua autoridade discricionária para execução de regras de imigração. Pelos planos agora levados a juízo, o DHS - Departamento de Segurança Nacional pode, por até três anos, não iniciar o processo de deportação dos indivíduos que não constituam uma ameaça aos Estados Unidos e preencham certos requisitos, esperando, assim, que o Congresso tenha tempo e vontade política para aprovar uma reforma legal mais ampla e permanente.

Para o governo, sua atitude em publicar as orientações nada mais é do que o cumprimento da cláusula constitucional de assegurar que as leis estejam sendo observadas, a chamada Cláusula do Cuidado, cujo conteúdo é esclarecido na sequência. Para os Estados autores da ação, o governo extrapolou essa cláusula ao abusar de seu poder discricionário e, em verdade, determinando algo que não está previsto em lei. Assim, enquanto para o governo, ele está dando orientações de como cumprir a lei diante dos escassos recursos - ou seja, da impossibilidade de deportar todos os imigrantes sem autorização, para os opositores, o governo usa sua discricionariedade para deixar de cumprir a lei. $\mathrm{O}$

19 CROW, Melissa. Symposium: Back to immigration basics - Why the DAPA/DACA case is simpler than it seems, SCOTUSblog (Feb. 10, 2016, 12:55 PM). Disponível em: <http://www.scotusblog. com/2016/02/symposium-back-to-immigration-basics-why-thedapadaca-case-is-simpler-than-it-seems/. Acesso em: 20 fev. 2016. governo afirma que está no exercício legal da chamada 'prosecutorial discretion', termo que tem origem nos poderes discricionários do promotor de justiça ${ }^{20}$, ao decidir se irá ou não propor ação em face de alguém ${ }^{21}$. O termo é amplamente utilizado nos Estados Unidos para definir os poderes dos promotores e é estendido, sem muita dificuldade, às autoridades administrativas ${ }^{22}$ que se deparam, no dia a dia de suas atividades, com a necessidade de tomar decisões sobre iniciar ou não um procedimento de remoção de um indivíduo do território; conceder ou não um documento; parar um indivíduo para perguntas, entre outras.

Na prática, os oficiais dos serviços de imigração têm autoridade para decidir, diante de um caso concreto, se darão inicio ou não ao processo de deportação, o que, normalmente, ocorre com uma notificação para apresentação à Corte de Imigração, com fundamento em uma violação das leis de imigração, por exemplo, não possuir o documento que permita sua estadia. Essa discricionariedade envolve a análise de diversos fatores, como o fato de o indivíduo estar ou não estudando, as circunstâncias que o fizeram vir para os Estados Unidos, se a pessoa ou algum familiar seu serviu para as Forças Armadas americanas, se a pessoa tem cônjuge ou filho, ou parente que tenha a residência permanente no país, o tempo que decorreu desde sua chegada, entre vários outros critérios. A utilização conjugada deles permite que o oficial tome sua decisão.

Nas palavras de Kate M. Manuel e Todd Garvey ${ }^{23}$, o termo "...é comumente utilizado para descrever a ampla latitude que promotores tem em determinar quem, de

20 Sobre a origem do termo e seu significado em relação ao promotor de justiça, ver BUBANY, Charles P.; SKILLERN, Frank F. Taming the dragon: an administrative law for prosecutorial decision. Criminal Law Review, v. 13, p. 473-505, 1976.

21 Para uma excelente explicação do conteúdo e dos limites dessa discricionariedade no direito de imigração, ver WADHIA, Shoba Sivaprasad. The Role of Prosecutorial Discretion in Immigration Law. 31 Immigration \& Nationality Law Review, p. 981, 2010.

22 MANUEL, Kate et al. Prosecutorial Discretion in Immigration Enforcement: Legal Issues, Congressional Research Service, 7-5700, p. 3, cita os seguintes casos: Caso da Remoção dos Chineses, 130 U.S. 581, 604, 1889 , onde a Corte afirma que o Congresso tem o poder para elaborar leis que determinem a remoção de trabalhadores chineses; o caso Fong Yue Ting vs. United States, 149 U.S. 698, 705-09, 1893, onde a Corte afirma o poder do Congresso para deportar estrangeiros.

23 Tradução livre de: “...is commonly used to describe the wide latitude that prosecutors have in determining when, whom, how, and even whether to prosecute apparent violations of the law." Prosecutorial Discretion in Immigration Enforcement: Legal Issues, Congressional Research Service, 7-5700, pp. 1. 
quem, como, e mesmo se ajuizarão ações por aparentes violações da lei."

Todavia, deve-se ter em mente que não é figura típica do direito de imigração, mas sim do direito criminal. Neste texto, e após essa explicação, falar-se-á, somente, em 'discricionariedade', entre aspas, indicando ao leitor que trata-se deste conceito específico. Parece não haver dúvidas de que alguns membros do Poder Executivo detenham essa 'discricionariedade'. Se o Congresso tem o poder de estabelecer as condições sob as quais um estrangeiro pode entrar no país, tais condições podem ser executadas, exclusivamente, por membros do executivo. Foi o que a Suprema Corte definiu no caso Lem Moon Sing vs. Estados Unidos ${ }^{24}$ reconhecendo, inclusive, que o judiciário não tem poder para revisar as decisões dos oficiais de imigração sobre a admissão de estrangeiros no país.

Os Estados alegam que o Presidente não pode lançar mão da 'discricionariedade' porque ela só é admitida para abrir exceções ou para esclarecer a aplicação da lei, em casos individuais. Alegam que as orientações do Executivo nos planos objetos da ação se aplicam a uma generalidade de casos, atingindo um grande grupo de pessoas, o que leva à invalidade do uso da 'discricionariedade'. O governo, a seu turno, afirma que os planos trazem orientações com critérios que permitem a postergação do processo de deportação que só podem ser aplicados se cada caso for analisado individualmente. Há alegações de que uma das provas de que o plano não é feito para ser aplicado caso a caso é que menos de um por cento de todas as aplicações para reconhecimento do direito de postergação da deportação foram denegadas. Ora, se a imensa maioria foi contemplada com o direito à deportação, isso implicaria uma suspensão dos termos da lei que estabelece a deportação para uma classe de imigrantes ilegais que atendem aos critérios expostos pelo Presidente ${ }^{25}$. Mas pode não ser exatamente esse o caso. $\mathrm{O}$ fato de que um grande número de pessoas consegue ser beneficiado pelo plano do governo não precisa significar que suas regras estão escritas de modo a atingir uma classe de pessoas. Importa saber

24 O exemplo está em MANUEL, Kate et al. Prosecutorial Discretion in Immigration Enforcement. Legal Issues, Congressional Research Service, 7-5700, p. 8.

25 EASTMAN, John. Symposium: Barack Obama is not king, SCOTUSblog. Feb. 11, 2016, 1:19 PM. Disponível em: < http://www. scotusblog.com/2016/02/symposium-barack-obama-is-not-king $>$. Acesso em: 20 fev. 2016. se os oficiais, na execução das orientações do Executivo, precisam analisar cada caso para definir se irão ou não iniciar o procedimento de deportação. Se há um grande número de beneficiados, a conclusão lógica é que há um grande número de pessoas que atendem os critérios, mas não que a dicção das orientações estabeleçam critérios aplicáveis a todo um grupo. Nesse sentido e em seu benefício, o governo tem a própria letra do texto que editou, que, expressamente, prevê que a aplicação dos critérios deve ser feita com a análise casuística. É claro que a Suprema Corte pode decidir por não adentrar neste assunto, alegando que se trata de questão política, definida tão somente no âmbito do poder executivo, deixando de estar ao alcance do Judiciário ${ }^{26}$. Essa opção gera uma disputa bem conhecida, que é a da possibilidade, ou não, de o Poder Judiciário rever decisões políticas, ou políticas públicas, mas aqui, estabelecidas pelo Executivo. Mas, se enfrentar essa questão, a Suprema Corte deverá definir se o Presidente abusou de seu direito de usar a 'discricionariedade' e, nesse caso, se ele infringiu a norma constitucional denominada de 'Take Care Clause'. Essa cláusula, também chamada de "Cláusula de Execução Leal"27, está prevista na Constituição Americana, no Artigo II, Seção 3, que dita que o Presidente assegurará a leal execução das leis ${ }^{28}$.

Ela contém um dever que qualifica o poder executivo do Presidente. Nas palavras de Todd Garvey:

"Primeiramente, a Cláusula do Cuidado tem sido interpretada como estabelecendo uma obrigação para o Presidente e aqueles sob sua supervisão para cumprir e executar claramente as disposições legais da maneira como o Congresso as edita. Todavia, a Suprema Corte também construiu a Cláusula de maneira a dar ao Presidente controle sobre o cumprimento da lei federal." ${ }^{29}$

26 Sobre as questões políticas, ver o nosso PAMPLONA, Danielle Anne. O Supremo Tribunal Federal e a decisão de questões políticas. Curitiba: Juruá, 2011, em especial no segundo capítulo.

27 Tradução livre de "Faithful Execution Clause". A autora conscientemente não se utiliza do termo fiel, que parece fazer o termo mais sonoro no português, para não gerar a errônea impressão de que se trata da execução fiel da letra da lei. Não é essa a interpretação dada pelos doutrinadores, como se verá em seguida.

28 No original: "The President... shall take Care that the Laws be faithfully executed."

29 Tradução livre do original, onde se lê: "Primarily, the Take Care Clause has been interpreted as placing an obligation on both the President and those under his supervision to comply with and execute clear statutory directives as enacted by Congress. However, the Supreme Court has also construed the Clause as ensuring Presidential control over the enforcement of federal law." The Take Care Clause and Executive Discretion in the Enforcement of Law, p. 3-4. 
Em outras palavras, a cláusula obriga o Presidente a cumprir as leis, ao mesmo tempo em que estabelece o controle do Presidente sobre aqueles que devem fazer as leis serem cumpridas. No exercício desse poder, o Presidente pode executar ações e controlar a execução de ações por terceiros e, ainda, o Presidente tem o dever de exercitar o seu poder para assegurar que as leis sejam lealmente executadas. Estas já eram disposições das Constituições da Pensilvânia, de 1776 e de Nova Iorque, de 1777, que, ao organizar o poder executivo, determinavam que ele executasse as leis com lealdade. Os debates da constituinte, também, indicam que a compreensão geral era que o Presidente tinha o dever de cuidar para que as leis fossem lealmente executadas ${ }^{30}$.

Ocorre que a extensão com que o Presidente lealmente executa as leis não é clara; mas é certo que o Presidente não precisa fazer cumprir cada lei em sua total extensão. O senso comum sugere que o Presidente possa ter alguma discrição ${ }^{31}$ para poder aferir custos e benefícios do cumprimento de uma lei. Mas já em 1838, no caso Kendall vs. Estados Unidos ex rel. Stokes ${ }^{32}$, a Suprema Corte - em resposta ao argumento do governo de que essa cláusula era fonte de poder para o Presidente - definiu que "defender que a obrigação imposta ao Presidente de cuidar para que as leis sejam lealmente executadas, implica que ele tenha poder para proibir sua execução, é uma nova definição da Constituição, e inteiramente inadmissível'"33, ou seja, a 'discricionariedade' não per-

30 WILSON, James. Lectures on Law Part 2, in Collected Works. 2007. p. 878 .

31 No ordenamento Americano não há disputa acerca da existência da discricionariedade, mas sim alguma disputa acerca de sua extensão. O Presidente não precisa fazer cumprir a lei sempre que ele entenda que há uma violação eis que, ainda que tenha a obrigação de executar fielmente as leis, ele pode, por exemplo, perdoar uma ofensa mesmo antes de um julgamento. Isso porque a Constituição prevê a denominada cláusula de perdão, quando em seu Artigo 2, Sessão 2, Cláusula 1 dita, em tradução livre, que o Presidente terá poder para conceder prorrogações e perdões por ofensas contra os Estados Unidos...”, no original : "The President..... shall have Power to grant Reprieves and Pardons for Offences against the United States...". Disponível em: <http://constitutionus.com>. Acesso em: 10 fev. 2016.

32 Nesse caso, o Diretor-Geral dos Correios se negou a fazer um pagamento determinado pelo Tesouro Nacional - com fundamento em lei, a alguns contratantes com o service postal. O Diretor- Geral se dizia sob as ordens do Presidente e a Corte decidiu que o Presidente não tinha poderes para determinar o não cumprimento de uma lei. Disponível em:

$<$ https://www.law.cornell.edu/supremecourt/text/37/524>. Acesso em: 05 fev. 2016.

33 Tradução livre do original: "To contend that the obligation imposed on the President to see the laws faithfully executed, implies mite o total não cumprimento da lei. Assim, há quem advogue que as orientações do Presidente são, em verdade, verdadeiras suspensões da aplicação dos termos da lei que prevê remoção de estrangeiros ilegais. Nesse sentido, a ação deliberada do Presidente de não fazer cumprir parte de uma legislação seria uma violenta quebra de sua obrigação constitucional de fazer cumprir as leis ${ }^{34}$.

Essa cláusula tem um significado importante para a construção do conteúdo do princípio da separação de poderes eis que assim como o Congresso não pode fazer cumprir leis ou interferir no modo como o Presidente as cumpre, o Presidente e seus subordinados não podem criar leis, unilateralmente, descumprindo, emendando ou revogando uma lei editada pelo Congresso ${ }^{35}$.

No caso em questão, o problema será determinar se os poderes entregues ao Congresso, e somente a ele, para elaborar a lei e o poder do Presidente em fazê-la cumprir foram observados. Se os Estados puderem demonstrar à Suprema Corte que o Presidente afastou o cumprimento da lei de imigração que impõe a deportação em determinados casos, o governo estará diante de uma grande derrota, mas muito pequena diante da derrota que será imposta aos direitos humanos e aos imigrantes sem documentação em território americano.

Resta claro que a consolidação de leis de imigração não responde às necessidades correntes, pelo simples fato de que não foi desenhada para tanto. Sendo um conjunto de normas escritas há mais de cinquenta anos, há muitas lacunas, além disso, falta-lhe unicidade e consequentemente, clareza. Mas ela deixa ao encargo do administrador um plexo de decisões. E é justamente no exercício decorrente desta possibilidade que agora, o Governo Federal, fundamenta a necessidade de manter os planos elaborados e de colocar em prática as orientações, em especial, diante da impossibilidade de obter sucesso, junto a um Congresso majoritariamente de oposição, para fazer modificações mais substanciais, que exigiriam alterações legislativas.

a power to forbid their execution, is a novel construction of the constitution, and entirely inadmissible.” Disponível em: <https:// www.law.cornell.edu/supremecourt/text/37/524>. Acesso em: 05 fev. 2016.

34 DELAHUNTY, Robert J.; YOO, John C. Dream on: The Obama administration's non enformcement of immigration laws, the Dream Act, and the Take Care clause. Texas Law Review, v. 91, p. 785. 35 GARVEY, Todd. The Take Care Clause and Executive Discretion in the Enforcement of Law. Congressional Research Service, 7-5700, p. 1-38, 2014. Disponível em: <https://www.fas.org/sgp/crs/misc/ R43708.pdf >. Acesso em: 20 fev. 2016. p. 5. 


\subsection{Da Lei de Procedimentos Administrativos}

A lei que regulamenta processos administrativos ${ }^{36}$ tem duas disposições importantes para o caso. Em primeiro lugar, essa lei retira das mãos do Judiciário a possibilidade de decidir sobre algumas questões, assim, é possível que a Corte enfrente se pode ou não se manifestar sobre as orientações editadas pelo Presidente. Há precedente que estabelece que se o Presidente realmente está no uso da 'discricionariedade', ele deverá se submeter a essa legislação, conforme definido Jordan vs. Estados Unidos, decidido no final da década de 70 do século passado, em que já foi estabelecido que ao usar a 'discricionariedade' o ato se sujeita à Lei de Procedimentos Administrativos ${ }^{37}$. Mas há, também, precedente que, sem entrar na questão da discricionariedade, classifica o ato de conceder a postergação do ato de deportação como não sujeito à revisão judicial, conforme decidiu a Suprema Corte em Reno vs. Comitê pela Não-discriminação de Árabes-americanos, há quase duas décadas ${ }^{38}$.

Em segundo lugar, a legislação mencionada exige que a determinados atos seja dada publicidade antes de sua execução. A publicidade, no caso, é determinada não só para dar a todos conhecer o teor do ato, mas para permitir que as pessoas possam questioná-lo, o que não ocorreu no presente caso. O Governo tem, a seu favor, a definição de que a publicidade prévia dos atos só é exigida daqueles que tem potencial para restringir direitos, como já foi decidido em casos como Lewis vs. Weinberger ou Berends vs. Butz ${ }^{39}$. É evidente que as orientações constantes nos planos editados não restringem direitos, ao contrário, reconhecem um direito humano essencial, o da dignidade dos indivíduos, que

36 Em inglês, Admnistrative Procedure Act. Disponível em: $\quad<$ https://www.justice.gov/sites/default/files/jmd/legacy/2014/05/01/act-pl79-404.pdf>. Acesso em: 20 fev. 2016.

37 O caso está bem explicado, em suas origens, em NEUMANN JUNIOR, Richard K. The New Era of Administrative Regularization: controlling prosecutorial discretion through the Administrative Procedure Act. University of Daytona Law Review, v. 3, n. 1, p. 23-57, 1978. p. 43.

38 Como lembra CROW, Melissa. Symposium: Back to immigration basics - Why the DAPA/DACA case is simpler than it seems, SCOTUSblog (Feb. 10, 2016, 12:55 PM). Disponível em: < http://www. scotusblog.com/2016/02/symposium-back-to-immigration-basicswhy-the-dapadaca-case-is-simpler-than-it-seems/. Acesso em: 20 fev. 2016.

39 Ambos mencionados por NEUMANN JUNIOR, Richard K. The New Era of Administrative Regularization: controlling prosecutorial discretion through the Administrative Procedure Act. University of Daytona Law Review, v. 3, n. 1, p. 26, 1978. demanda que possam viver sem a sombra, sem o peso, sem o medo de serem deportados a qualquer instante. A dificuldade está em saber se as orientações do Presidente serão, realmente, compreendidas como exercício de seu poder 'discricionário'. A partir daí, considerar as orientações válidas ou não será consequência da opção adotada.

\section{Considerações Finais}

$\mathrm{Na}$ escolha do Presidente Obama, ele levou em consideração que há um número enorme de imigrantes que estão irregularmente no país por diferentes motivos e em diferentes situações. Alguns podem ter filhos americanos; ou estão no país porque cuidam de uma pessoa idosa, que não tem condições físicas e mentais de um recomeço ou de uma viagem; ou porque elas mesmas são idosas. Ao se deparar com tais situações, e compará-las com a situação de imigrantes ilegais que são criminosos ou representam um risco à segurança nacional, a opção foi concentrar o orçamento e os esforços para expulsão destes últimos em detrimento dos primeiros. Assim, o plano do Executivo descreve quais são os indivíduos que não devem gerar esforços do Departamento de Segurança Nacional para expulsão, permitindo que os esforços sejam concentrados sobre outros casos que ainda assim, abrangerão milhares de pessoas.

A comunidade que presta auxílio diariamente a esses milhões de imigrantes, os estudiosos do tema, os defensores de direitos humanos, só podem esperar que a Suprema Corte decida esse caso como já o fez em Arizona vs. Estados Unidos. Nesse caso, determinou-se que os oficiais de imigração detêm autoridade para decidir pela não deportação de alguns estrangeiros e que isso pode ser reflexo de preocupações com direitos humanos mais urgentes e pela análise das características individuais de cada imigrante, como o nascimento de um filho em solo americano ou suas ligações com a comunidade ${ }^{40}$.

Espera-se que a Suprema Corte reconheça o poder do Presidente para editar os planos DACA e DAPA e que ele o fez com respeito à cláusula do cuidado, atento à necessidade de cumprir a legislação aprovada pelo Congresso Nacional. Além disso, espera-se que a Supre-

40 The SUPREME COURT OF UNITED STATES. Caso Arizona vs. Estados Unidos. Disponível em: < https:/ /www.law.cornell. edu/supremecourt/text/11-182. Acesso em: 25 fev. 2016. 
ma Corte reconheça que não houve qualquer ilegalidade perante a Lei de Procedimentos Administrativos.

Ao fim, trata-se de passar a enxergar os imigrantes e a dedicar aos mesmos políticas positivas, ao contrário do que tem feito o legislativo. Ainda que, de alguma forma, o silêncio do Congresso Nacional ao não dedicar os recursos necessários para expulsão desse imigrantes, seja também uma forma de regulamentar sua vida em solo americano, a atual política legislativa faz vistas grossas à sua existência. Sem dúvidas, a manutenção dos planos representará um avanço para o reconhecimento da existência e para a proteção de direitos humanos.

\section{REFERÊNCIAS BIBLIOGRÁFICAS}

AMERICAN IMMIGRATION COUNCIL. Understanding Prosecutorial Discretion in Immigration Law. Report 09.09.11. Disponível em: <http://www.immigrationpolicy.org/just-facts/understanding-prosecutorial-discretion-immigration-law>. Acesso em: 05 jun. 2016.

BUBANY, Charles P.; SKILLERN, Frank F. Taming the dragon: an administrative law for prosecutorial decision. Criminal Law Review, v. 13, p. 473-505, 1976.

CROW, Melissa. Symposium: Back to immigration basics - Why the DAPA/DACA case is simpler than it seems, SCOTUSblog (Feb. 10, 2016, 12:55 PM). Disponível em: <http://www.scotusblog.com/2016/02/ symposium-back-to-immigration-basics-why-the-dapadaca-case-is-simpler-than-it-seems/. Acesso em: 20 fev. 2016.

DELAHUNTY, Robert J.; YOO, John C. Dream on: The Obama administration's non enformcement of immigration laws, the Dream Act, and the Take Care clause. Texas Law Review, v. 91, p. 781- 857,

EASTMAN, John. Symposium: Barack Obama is not king, SCOTUSblog. Feb. 11, 2016, 1:19 PM. Disponível em: <http://www.scotusblog.com/2016/02/symposium-barack-obama-is-not-king $>$. Acesso em: $20 \mathrm{fev}$. 2016.

GARVEY, Todd. The Take Care Clause and Executive Discretion in the Enforcement of Law. Congressional Research Service, 7-5700, p.1-38, 2014. Disponível em: <https:/ / www.fas.org/sgp/crs/misc/R43708.pdf >. Acesso em: 20 fev. 2016.
HOEFER, Michael; RY'TINA, Nancy; BAKER, Bryan. Estimativa da população de imigrantes sem autorização vivendo nos Estados Unidos. Escritório de Estatísticas do Departamento de Segurança Nacional. Disponível em: < http:/ / www.dhs.gov/xlibrary/assets/statistics/publications/ ois_ill1pe 2011.pdf>. Acesso em: 20 fev. 2016.

MANUEL, Kate M.; GARVEY, Todd. Prosecutorial Discretion in Immigration Enforcement: Legal Issues. Congressional Research Service, 7-5700, p. 1-28, 2013. Disponível em: <https://www.fas.org/sgp/crs/misc/R42924. pdf $>$. Acesso em: 20 fev. 2016.

National Archives and Records Administration. Constituição dos Estados Unidos. Disponível em: <http://www. archives.gov/exhibits/charters/constitution_transcript.html>. Acesso em: 15 jan 2016.

NEUMANN JUNIOR, Richard K. The New Era of Administrative Regularization: controlling prosecutorial discretion through the Administrative Procedure Act. University of Daytona Law Review, v. 3, n. 1, p. 23-57, 1978.

OBAMA, Barack. Pronunciamento à nação em 20.11.2014. Disponível em: <https://www.whitehouse.gov/thepress-office/2014/11/20/remarks-president-address-nation-immigration>. Acesso em: 10 jan. 2016.

PAMPLONA, Danielle Anne. O Supremo Tribunal Federal e a decisão de questões políticas. Curitiba: Juruá, 2011.

PEW RESEARCH CENTER. What do we know about illegal immigration from Mexico? Disponível em: < http:// www.pewresearch.org/fact-tank/2015/11/20/what-we-know-about-illegal-immigration-from-mexico/. Acesso em: 25 jan. 2016.

Supreme Court of the United States. Blog, United States v. Texas. Disponível em: < http:/ /www.scotusblog.com/ case-files/cases/united-states-v-texas/. Acesso em: 25 fev. 2016.

Supreme Court of the United States. Caso Heckler vs. Cheney. Disponível em: <https://supreme.justia.com/ cases/federal/us/470/821/case.html. Acesso em: 15 fev. 2016.

Supreme Court of the United States. Caso Kendall vs. Estados Unidos ex rel. Stokes. Disponível em: <https:// www.law.cornell.edu/supremecourt/text/37/524. Acesso em: 05 fev. 2016.

Supreme Court of the United States. Caso Texas vs. Estados Unidos. Disponível em: <http://www.scotusblog. $\mathrm{com} /$ case-files/cases/united-states-v-texas/>. Acesso: 
em 25 fev. 2016.

SUPREME COURT OF UNITED STATES. Caso Arizona vs. Estados Unidos. Disponível em: <https:// www.law.cornell.edu/supremecourt/text/11-182. Acesso em: 25 fev. 2016.

The Supreme Court of United States. Arguments Transcripts. Argument Session: April 18, 2016, p. 46. Disponível em: <http://www.supremecourt.gov/oral_arguments/argument_transcripts/15-674_h3dj.pdf $>$. Acesso em: 05 jun. 2016.

THE UNITED STATES Department of Homeland Security. Immigration and Nationality Act. Disponível em: <https://www.uscis.gov/ilink/docView/SLB/ HTML/SLB/act.html>. Acesso em: 05 jun. 2016.

THE UNITED STATES. Administrative Procedure Act. Disponível em: <https://www.justice.gov/sites/default/files/jmd/legacy/2014/05/01/act-pl79-404. pdf>. Acesso em: 20 fev. 2016.

THE UNITED STATES. The United States Constitution. Disponível em: <http://constitutionus.com>. Acesso em: 10 fev. 2016.

WADHIA, Shoba Sivaprasad. The Role of Prosecutorial Discretion in Immigration Law. 31 Immigration \& Nationality Law Review, p. 961-1017, 2010.

WERMUTH, Maiquel Ângelo Dezordi. Direito penal (do autor) e imigração irregular na União Européia: do "descaso" ao "excesso" punitivo em um ambiente de mixofobia. Revista de Direito Internacional, v. 8, n. 2, p. 167-204, 2011. Disponível em: <http://www.publicacoesacademicas.uniceub.br/index.php/rdi/article/ view/1548>. Acesso em: 05 jun. 2016.

WILSON, James. Lectures on Law Part 2, in Collected Works. 
Para publicar na Revista de Direito Internacional, acesse o endereço eletrônico www.rdi.uniceub.br ou www.brazilianjournal.org.

Observe as normas de publicação, para facilitar e agilizar o trabalho de edição. 